\section{POSFOLKLORE: RAÍCES Y GLOBALIZACIÓN EN LA MÚSICA POPULAR CHILENA}

\author{
Juan Pablo González \\ P. Universidad Católica de Chile. Diapente XXI \\ jgonzaro@uc.cl
}

\begin{abstract}
This article discusses the development of the concept of folk roots, introduced by Chilean singer-songwriters in the mid-seventies, as a strategy to legitimize their divergent practice from the norm of folklore in times of military rule. The institutionalization of this concept with the return of democracy in the early nineties and its continued tightening from a third generation of Chilean singersongwriters and bands derivatives from theater companies, allow us to discuss the problem of folk roots in times of globalization. We propose the concepts of posfolklore and hydroponic roots, attached to the trend of Chilean listeners and musicians to incorporate world music to their artistic practices and consumption. These concepts would facilitate the discussion of the mixing of influences in Chilean music and the consequent proliferation of intermediate rather than hegemonic identities in contemporary Chilean culture.
\end{abstract}

KEY WORDS: Postmodernism; globalization; nation; Chile; identity; folk; pop music; singer-songwriter; gypsy music.

Escribir sobre el presente supone el riesgo de quedar obsoleto de los anaqueles académicos con cierta rapidez, en especial al tratar fenómenos ligados a la música popular, una música muy dependiente de las nuevas tecnologías y los cambios que éstas producen en los modos de producción y en los hábitos de consumo. Desde esta perspectiva, por ejemplo, resulta inconcebible un presente como el de 2010 tal como lo podiamos haber imaginado a comienzos de este nuevo siglo. Debido a eso y a mi propia (de)formación como historiador de la música, requiero tomar impulso en el pasado para intentar llegar al presente'.

En paises de un alto consumo de músicas extranjeras, como es Chile, los fenómenos de mezcla e hibridación han estado a la orden del día, produciendo pugnas entre la construcción hegemónica y subalterna de identidades. En este artículo, abordo el fenómeno de la hibridación

\section{POSFOLKLORE: ROOTS AND GLOBALIZATION IN CHILEAN POPULAR MUSIC}

RESUMEN: Este artículo aborda el desarrollo del concepto de raíz folklórica, introducido por cantautores chilenos a mediados de los años setenta, como estrategia para legitimar corrientes divergentes del folklore de la norma imperante en tiempos del régimen militar. La institucionalización de este concepto con el retorno a la democracia y su continuo tensionamiento desde una tercera generación de cantautores nacionales y desde los nuevos grupos musicales derivados de compañías teatrales, permite reflexionar sobre el problema de las raices en tiempos de globalización. Se proponen los conceptos de posfolklore y de raíces hidropónicas, adscritos a la permanente tendencia del músico y del auditor chileno a incorporar músicas de mundo a su práctica y consumo musical. Estos conceptos permiten discutir las mezclas en la música chilena y la consiguiente multiplicación de identidades intermedias más que hegemónicas en la cultura chilena contemporánea.

PALABRAS CLAVE: Posmodernidad; globalización; nación; Chile; identidad; folklore; música popular; cantautor; música gitana.

musical y sus agendas políticas asociadas desde el concepto de raíz folklórica, el que desde mediados de los años setenta ha servido de marco legitimador para una serie de mezclas desarrolladas por músicos chilenos que han ampliado notoriamente tanto el concepto de folklore como el de raíz.

\section{FOLKLORE DE MASAS}

La consolidación de la industria musical en América Latina se produjo en la década de 1920 con el pleno funcionamiento e interacción de seis industrias culturales interconectadas. Las cuatro principales fueron los lugares de baile y diversión, donde confluian espacios tradicionales con los nuevos espacios cosmopolitas; la industria disco- 
gráfica, instalada en la región desde comienzos de siglo; la radiodifusión, que se iniciaba en manos de técnicos y artistas voluntarios; y un sistema artístico, productivo y de consumo desarrollado en lberoamérica a partir del auge del cuplé, de los espectáculos de variedades, de las compañías de revista y del circo: el star system. A esto se suma la plena vigencia de la partitura de una hoja como portadora de letra, música, visualidad, discurso y forma de consumo de la canción popular, junto a la incorporación del cine mudo y sonoro como medio, evento y sentido para la música en general.

La música de tradición oral no podía sustraerse a estas influencias, sustentadas tanto con la inmigración rural como con el desplazamiento ocasional de habitantes urbanos hacia pueblos y haciendas de la zona central de Chile. Estos habitantes eran portadores de medios, prácticas y formas de consumo que anunciaban y preparaban la expansión de la industria musical por todo el territorio. Al regresar a la ciudad, estos sujetos traían repertorio, géneros, bailes, formas de interpretación y usos folk, que servirán de sustento para la construcción de los emblemas sonoros de la nación.

Cuando la industria comience a absorber repertorio de tradición oral -definido como folklore desde la modernidad-, no se pondrá en duda si lo que se escucha en un teatro, un disco o por la radio sea o no folklore, puesto que se trataba de músicos tradicionales que sólo habían sido trasplantados al estudio de grabación, como quien transplanta un filodendro a un invernadero sin que pierda la condición de tal. Esto, reconociendo además la porosidad que tiene la ciudad en las zonas de mataderos, mercados, puertos, y suburbios, donde se instalaban chinganas o tabernas, quintas de recreo y casas de canto, animadas por genuinos exponentes de la tradición oral.

Las cantoras campesinas trasplantadas a la ciudad fueron paulatinamente reemplazadas por folkloristas, dedicadas al rescate y proyección de la tradición oral, quienes institucionalizaron su labor desde la academia y el Estado, mientras se mantenían insertas en la industria musical. De este modo, las folkloristas chilenas tendieron puentes entre investigación, extensión, difusión, proyección, educación y políticas públicas, contribuyendo a consolidar en la década de 1930 un concepto hegemónico de identidad sonora de la nación.

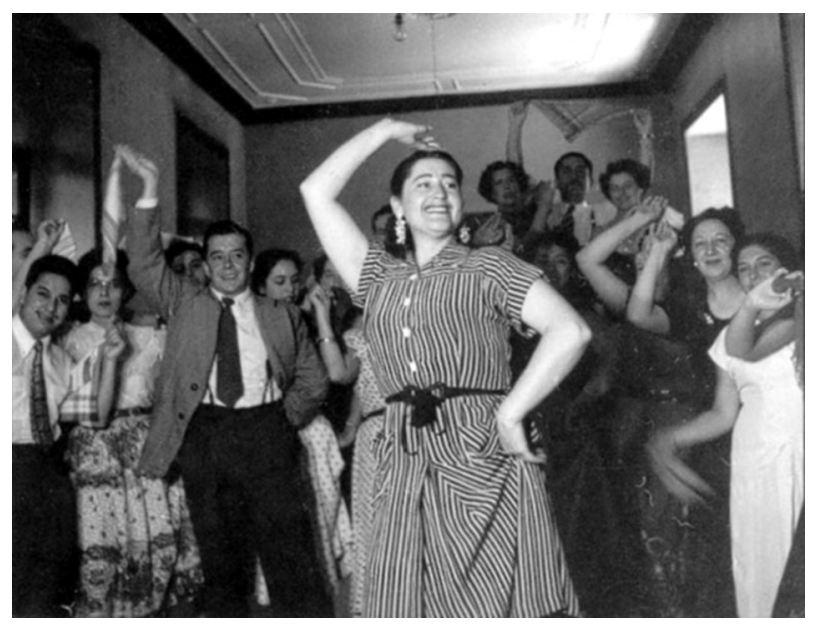

[1] La folklorista Margot Loyola enseñando a bailar cueca en los cursos de verano de la Universidad de Chile en 1954. Claro et al. 1989: 483 .

En este proceso, la industria creaba un nicho para la estrella del folklore, ya fuera una cantora campesina transplantada, la nueva folklorista o los cantantes y conjuntos folklóricos que estaban naciendo. Esto generará tensiones con el purismo folklorista avalado por el estado-nación, pero también oportunidades para la aparición de nuevos exponentes del folklore en la ciudad.

Éste fue el caso de los cuartetos vocales con guitarras ataviados a la usanza del huaso chileno -o hacendado y capataz-, primero formados por hombres y desde los años cincuenta incorporando una mujer como solista. Estos músicos fueron quienes desarrollaron una canción basada en el folklore, que fue plenamente absorbida por la industria musical y consumida por la población urbana y de inmigrantes rurales. Los conjuntos de huasos reafirmaban una identidad forjada en el campo, transformado en paraíso perdido y refugio imaginario para el inmigrante campesino ante el fragor e impersonalidad de la ciudad moderna. Tanto una tonada anónima interpretada por una cantora campesina o una tonada de autor grabada por un cuarteto de músicos vestidos de huasos, constituian medios legítimos de afirmación de su identidad. Incluso la tonada modernizada por los conjuntos de huasos expresaba para estos sectores su propia condición de sujetos campesinos transplantados al mundo moderno de la ciudad, facilitando también dicho transplante. 


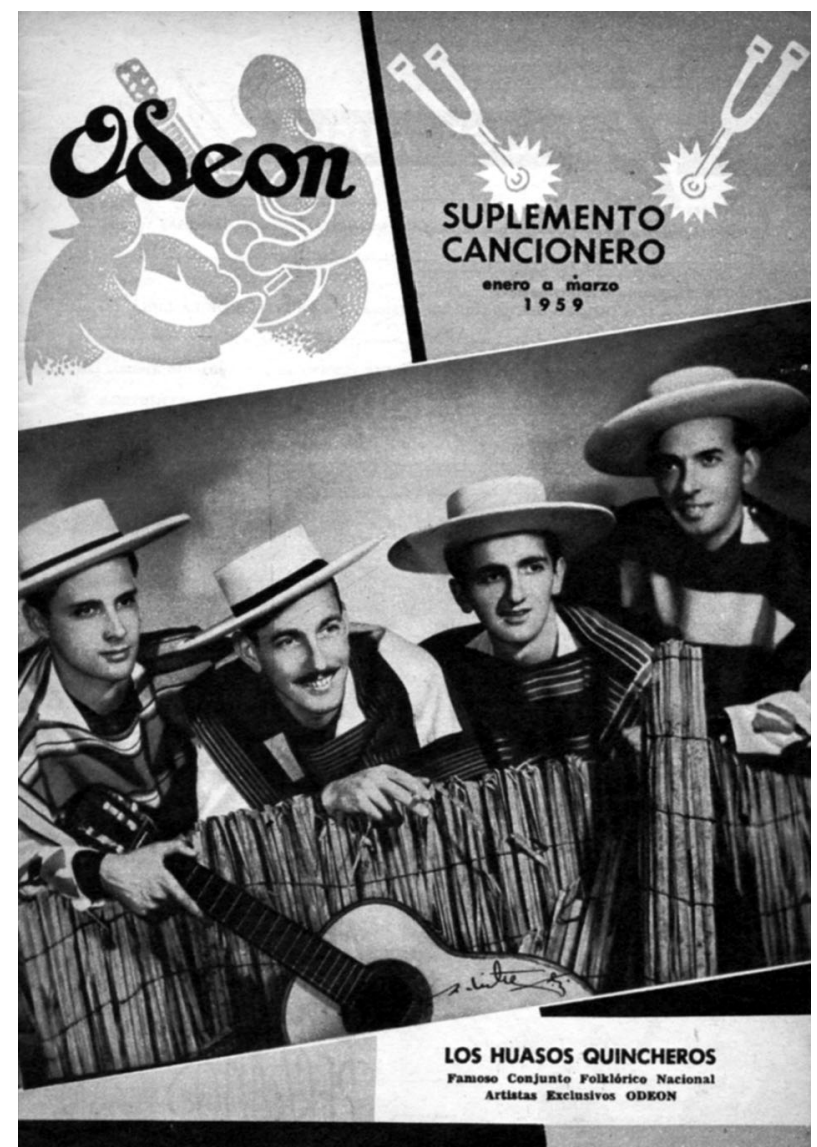

[2] Conjunto de música típica Los Huasos Quincheros en portada de Suplemento cancionero Odeon, enero-marzo 1959.

Desde la institucionalidad cultural del Estado, canalizada a través de la Universidad de Chile, se comenzó a diferenciar desde los años cuarenta tres tipos de folklore: el histórico 0 rescatado, el tradicional o vigente y el moderno o de autor. Los dos primeros fueron los promovidos por dicha institucionalidad. El folklore moderno será llamado música típica a partir de los años cincuenta, experimentando un fuerte desarrollo en manos de una industria musical cada vez más gravitante. El folklore histórico, en cambio, tenía menos visibilidad social, surgiendo del rescate realizado por los folkloristas de la memoria de sus cultores y también de los archivos literarios.

Este folklore será fuente renovadora para los movimientos de revival de los años cincuenta y sesenta, adquiriendo distintos sentidos en las tres tendencias predominantes: los conjuntos de proyección folklórica, creados bajo el amparo de los estudios de folklore; el Neofolklore, tendencia promovida por la industria musical que incorporaba repertorio del folklore a la música juvenil; y la Nueva Canción, movimiento de renovación estética e ideológica de la canción popular. En la proyección folklórica, el folklore adquirió un sentido didáctico y patrimonial; en el Neofolklore adquirió un sentido celebratorio de la diversidad; y en la Nueva Canción un sentido reivindicatorio de sujetos sociales excluidos por la modernidad. En los tres casos, se trata de una alteridad social y cultural encarnada por sujetos portadores de una tradición valorada como patrimonial y portadora de diversidad, pero socialmente discriminada.

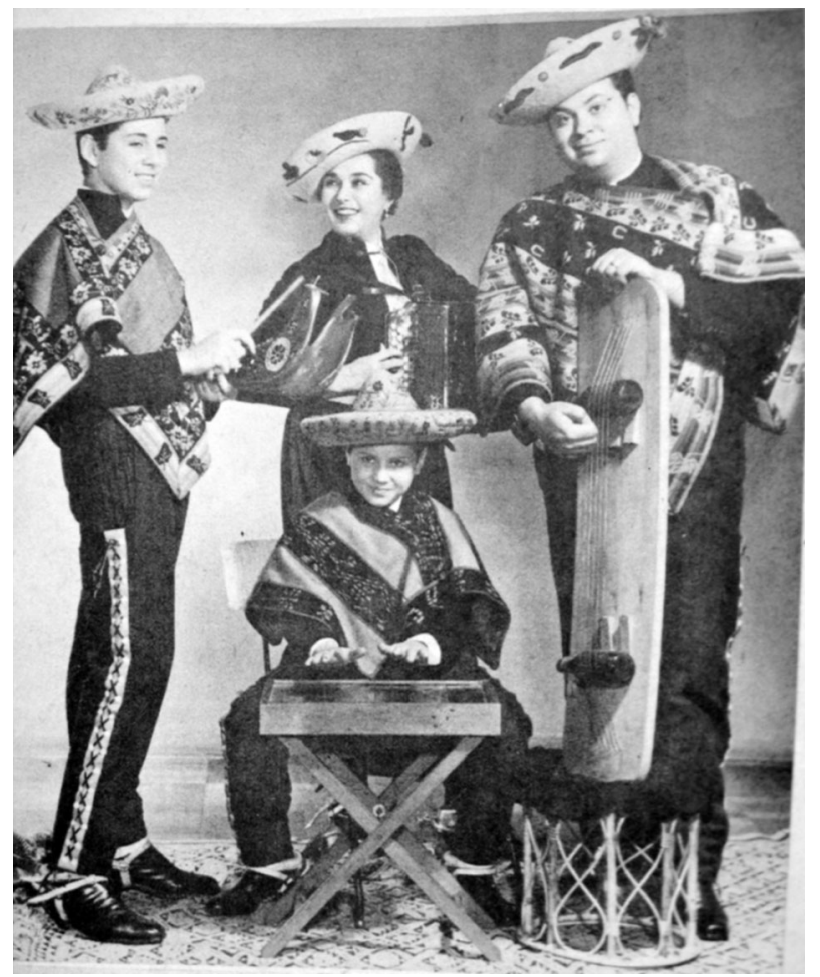

[3] Los De Ramón, grupo familiar de Neofolklore. Ritmo, 75, 2/2/1967.

De este modo, si bien la Nueva Canción señalaba la aparición de un movimiento que poseía un sentido crítico de la tradición, no se cuestionará demasiado la condición folklórica de esa canción, en especial al provenir de 
sujetos legitimados folklóricamente, como eran Violeta Parra y Víctor Jara, debido a su origen campesino, o Rolando Alarcón, dada su labor de folklorista y profesor de folklore.

\section{RaíceS LATINOAMERICANAS}

A mediados de los años sesenta, la canción chilena de autor contaba con raíces que se diversificaban, no sólo por el uso creativo del folklore histórico rescatado -en especial de géneros como el cachimbo, el trote, la refalosa, la pericona y la sirilla-, sino también por el incremento de música folklórica latinoamericana en la región. En efecto, el aumento de la circulación de folklore argentino -salteño y litoraleño- y andino -boliviano y peruano-, posibilitará encuentros, cruces e hibridaciones en los que los cantautores chilenos pondrán especial énfasis ${ }^{2}$. De este modo Violeta Parra cruzaba géneros del sur de Chile con instrumentos andinos; Víctor Jara fundía raíces rítmicas de distinto origen en un gran rasgueo americanista de $6 / 8$ más 3/4; Rolando Alarcón hacía confluir distintas rítmicas americanas en una misma canción; y Patricio Manns componía en 1965 su obra discográfica Sueño Americano, formada por doce canciones basadas en trazos rítmicos, armónicos y/o melódicos de distintos géneros folklóricos de la Patria Grande.

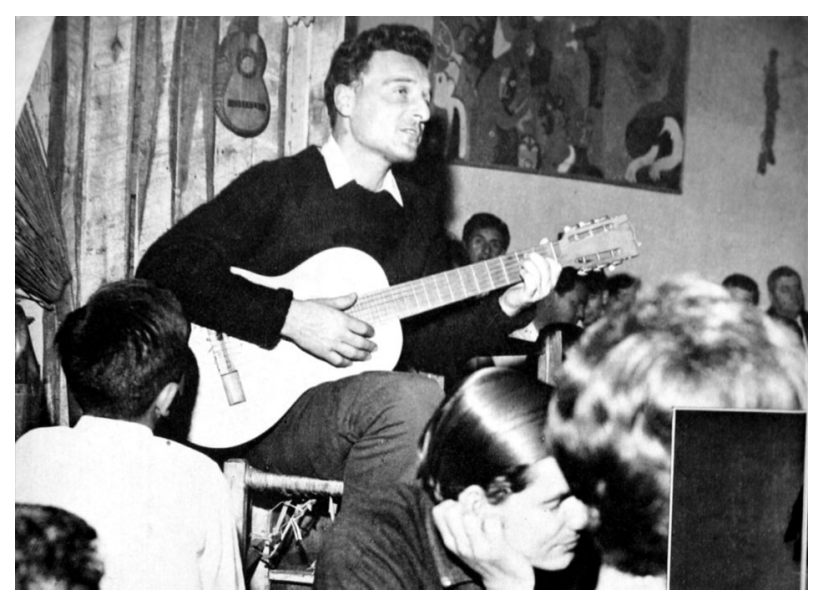

[4] Patricio Manns en La Peña de los Parra. En la pared cuelga un charango y una obra plástica de Violeta Parra. Rincón Juvenil, 44, $13 / 10 / 1965$.
Con la llegada de los militares al poder en septiembre de 1973, se debilitó el americanismo en la canción chilena, mientras se fortalecía un folklorismo de carácter nacionalista y patrimonial. Este folklorismo buscaba imponer desde el Estado, desde la educación y desde la industria musical la tradición criolla de la zona central del país, de fuerte ascendencia hispana y sin rasgos mestizos evidentes. Esta zona, que es donde se fundó la capital del país, ya era llamada Chile por los Incas cuando la descubrió Diego de Almagro en 1535, algo que gravitará en la conciencia identitaria de la nación. Se trata de una zona de tierra fértil y clima benigno, lugar privilegiado para su usufructo como encomienda, devenida en hacienda y fundo, y primer sostén de las grandes fortunas y familias chilenas. Estas familias serán las que ejerzan la influencia política y cultural gravitante en Chile hasta la década de 1920, retrocediendo parcialmente ante la irrupción de la cultura de masas, articuladora de influencias culturales y políticas de la clase media y de sectores obreros organizados.

Al año siguiente del golpe militar, la comisión organizadora del Festival de la Canción de Viña del Mar, decidió suspender la competencia folklórica que se venía realizando desde 1961, argumentando un escaso interés del público en ella, "que sólo inclinaba sus preferencias por canciones de corte internacional"3. En realidad, esta suspensión estaba sustentada en la reacción del folklorismo nacionalista a la incorporación de influencias latinoamericanas en la canción chilena y a la libertad con que se manejaban los rasgos del folklore local en ella. Al mismo tiempo, la canción basada en el folklore andino había alcanzado una fuerte connotación política a comienzos de los años setenta, algo que el nuevo régimen quería evitar. Como señala Karen Donoso, las nuevas autoridades militares consideraban que el folklore andino no era chileno y más bien les interesaba difundir el canto folklórico de la zona central. Este ambiente represivo y censor se mantuvo durante todo el régimen (1973-1988), señala Donoso, existiendo períodos de agudización y también de evidente contradicción ${ }^{4}$.

Éste fue el caso del boom andino que se vivió en Chile a mediados de los años setenta, en un período de fuerte represión militar, con grupos como Los Curacas (1967), Kollahuara (1974), Illapu (1974), Barroco Andino (1974) y Ortiga (1975) que continuaron su actividad de conciertos, de grabaciones $y$, en algunos casos, de presentaciones en televisión. Esto se suma a la reapertura de la peñas folkló- 
ricas y al inicio del movimiento de cantautores llamado Canto Nuevo. De este modo, en 1976 Illapu popularizó en Chile "Candombe para José" (1973), canción de inspiración afrouruguaya del argentino Roberto Ternán, grabada por el grupo en versión andina en su LP Despedida del pueblo (1976). "Candombe para José" era cantado en peñas universitarias, reuniones clandestinas y prisiones políticas, con el fervor de un himno de resistencia, mientras era ampliamente difundido por radio, incluso en una versión bailable en ritmo de cumbia a cargo del grupo Los Viking 5, que obtuvo Disco de Plata por ella ${ }^{5}$.

Es durante el boom de la música andina y la rearticulación del movimiento de cantautoría que nace el concepto de raíz folklórica. Esta iniciativa responde a una estrategia de la segunda generación de cantautores chilenos (19701980) agrupados en el Ilamado Canto Nuevo, para proteger y legitimar el campo de la canción de autor basada libremente en un folklore de distinta procedencia. Esto lo hacian en un contexto políticamente adverso y ante los cuestionamientos de autenticidad manifestados desde el purismo folklorista y nacionalista de la época.

\footnotetext{
"Fruto de debates, mesas, encuentros y todo tipo de instancias donde acudimos [en 1975], surgió llamar a nuestro canto 'de raiz' -afirma el cantautor Nano Acevedo-. En mi caso, defendi esto con bastante entusiasmo, pues una buena parte de mis temas, estaban basados en métrica del folklore, sin embargo tenía giros, modulaciones y estructuras que no se ajustaban a las danzas folklóricas" [Nano Acevedo, 8/7/2010].
}

Como señala la revista La Bicicleta, el folklore seguía siendo la base de este nuevo canto, "no en términos formales, sino que como actitud de búsqueda de lo auténtico, es decir, el lugar de donde se mira y se juzgan las demás expresiones que conforman nuestro universo cultural"6.

Respondiendo a la presión que el propio desarrollo de la canción de raíz estaba ejerciendo en los medios y eventos oficiales, el folklore regresó al Festival de Viña del Mar en 1980. Este regreso se produjo en dos etapas, primero con la participación en el acto inaugural del XXI Festival del Ballet Folklórico Nacional, creado bajo la influencia del Ballet Folklórico de México, que estilizaba, uniformaba y estetizaba las distintas manifestaciones de la cultura popular chilena.
Al año siguiente, se restituyó la competencia folklórica, que estuvo dominada por la participación de cantautores y grupos del Canto Nuevo, como Osvaldo Leiva, Natacha Jorquera, Santiago del Nuevo Extremo, Agua y, justamente, un grupo llamado Nuevas Raíces. La llegada de estos nuevos músicos al festival, llevó a la principal folklorista chilena e integrante del jurado, Margot Loyola, a afirmar en una conferencia de prensa en febrero de 1981 que, en rigor, el festival no acogía canciones folklóricas, sino composiciones de raíz folklórica ${ }^{7}$.

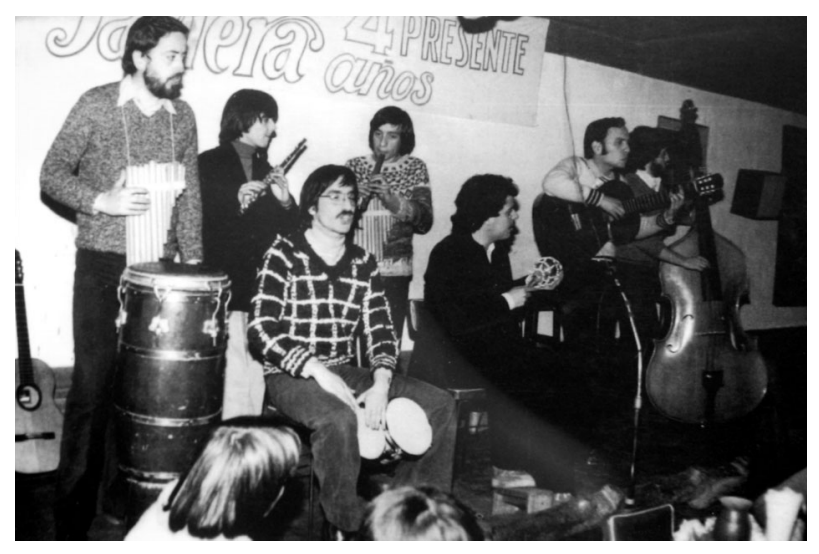

[5] Grupo de Canto Nuevo Aquelarre en 1979. Bravo y González, 2009.

El regreso del folklore al Festival de Viña, coincidia además con la aparición de nuevos programas de televisión dedicados al folklore, ya fuera en torno a la tertulia de un conjunto o mediante la realización de festivales televisados de canciones de raigambre folklórica. Se destacaron Cantares de Chile (1980) del Canal Nacional y Chilenazo (1980), del Canal la Universidad de Chile ${ }^{8}$.

Con el retorno de la democracia en 1989, el concepto de raíz folklórica continuó institucionalizando su uso en festivales, pero ahora expandiéndose a sociedades autorales, premios, industria musical, medios de comunicación, y en la labor educacional y cultural del Estado. De este modo, desde la plataforma de la industria musical, los medios de comunicación y el Estado era legitimada una categoría que venía siendo usada por los cantautores chilenos desde los años setenta y que alcanzará dimensiones insospechadas en las décadas por venir. 


\section{RAÍCES HIDROPÓNICAS}

Durante su exilio en Europa (1973-1989) los dos grupos principales de la Nueva Canción Chilena, Quilapayún e Intiillimani, habian continuado la apertura del folklore iniciada en Chile a comienzos de los años sesenta, incorporando ahora elementos mediterráneos, especialmente italianos y españoles, a su mezcla de raíces. En este caso, sólo debian justificarse ante sí mismos por esta inesperada expansión de la raíz latinoamericana, destacando la búsqueda de los universales del folklore, algo que la etnomusicología de los años setenta ya intentaba sistematizar'. Además, si "El pueblo unido jamás será vencido", como dice la canciónhimno de Sergio Ortega y Quilapayún, qué mejor manera de manifestar la unión de los pueblos que desde la unión de sus raíces.

Dentro de la permanente tendencia del músico y del auditor chileno a incorporar músicas del mundo a su práctica y consumo musical, dos nuevas maneras de concebir las raices marcarán la renovación de la escena musical nacional de la primera década del nuevo siglo. La primera y más visible corresponde a la llegada de una tercera generación de cantautores chilenos a partir de los años noventa, como Francisco Villa (1967), Manuel García (1970), Leo Quinteros (1975), Chinoy (1983), Nano Stern (1985) y Camila Moreno (1985) entre otros. Ahora sus raices no necesitarán de un territorio donde enraizar, más bien se nutren hidropónicamente de un folklore universal mediatizado. Con esta tercera generación de cantautores, las raíces comienzan a ser una opción personal más que colectiva, generándose redes sociales de opciones personales, que encuentran en la música su manifestación más efectiva para tejer comunidad desde el margen y la divergencia.

La segunda iniciativa de expansión de raíces en tiempos de globalización surgió de la práctica musical teatral. En efecto, el fortalecimiento de la escena teatral independiente desde el retorno de la democracia en 1989 y su interés por el arte circense, el teatro callejero, el pasacalle y el carnaval, hizo que las nuevas compañias privilegiaran la música en vivo en sus montajes. De este modo, estos artistas revivian la comunidad artístico-productiva autónoma de antigua data, pero ahora apoyada por fondos públicos concursables.

El teatro ya había influido en el desarrollo de la música popular chilena, especialmente a través del actor, director

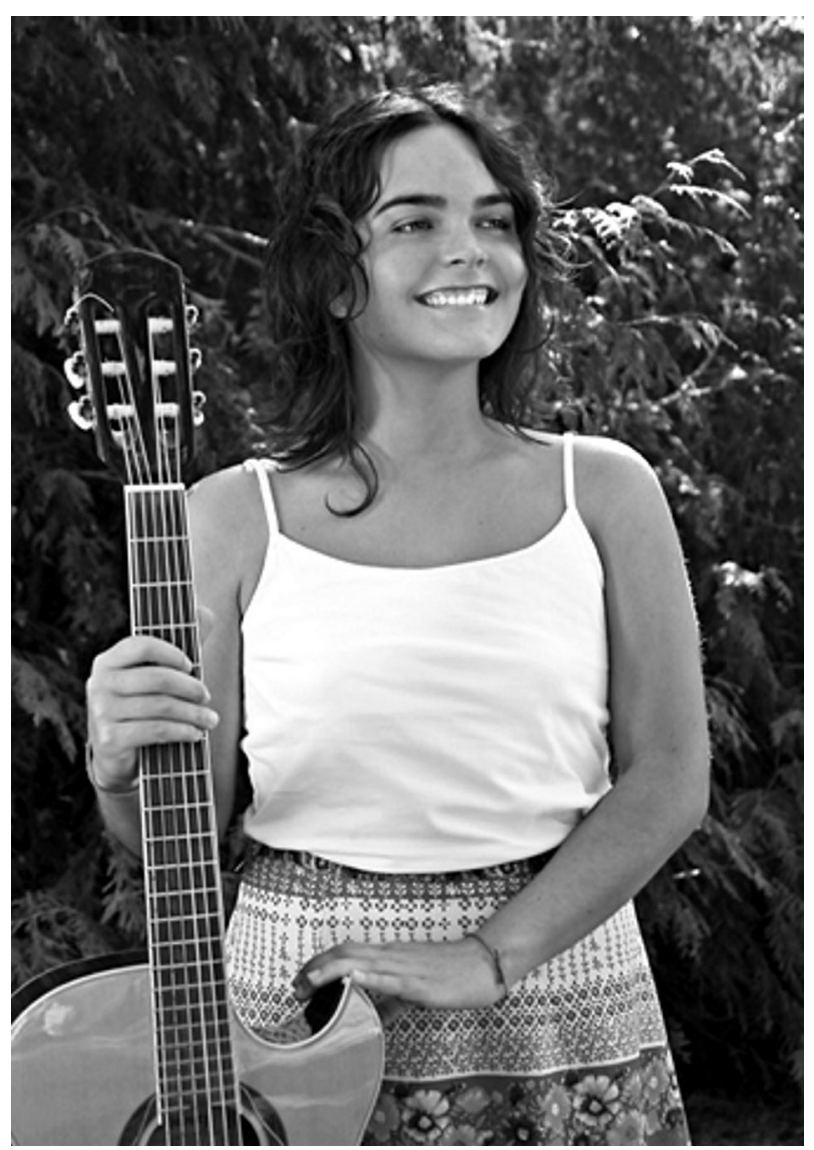

[6] Cantautora Camila Moreno. www.selloazul.cl [10/2010]

y cantautor Víctor Jara, quien había llevado las prácticas de la creación colectiva y el experimentalismo teatral de los años sesenta a música basada en el folklore. En su afán, usaba instrumentos folk de manera no idiomática en la música incidental de las obras que dirigía y escribía canciones que cruzaban libremente el folklore latinoamericano. Además, aplicó técnicas teatrales de ensayo y puesta en escena a Quilapayún primero e Inti-illimani después, como su director artístico, renovando el modo en que un grupo de música popular montaba un concierto sobre un escenario.

La apertura de la nuevas compañías independientes de los años noventa hacia el mundo popular universal, favoreció el desarrollo de distintas combinaciones instrumentales y sus consiguientes cruces musicales. Se trata de formatos provenientes de las banda de vientos -tanto andinas como 
gitanas-, de orquestas de baile de los años cincuenta y de grupos de rock post-punk. Fue el Gran Circo Teatro, fundado en Santiago en 1988 por Andrés Pérez a partir de su aprendizaje con Arianne Mousckinne y la Compañía Theatre du Soleil de París, el que instaló esta nueva práctica musical escénica, en especial a partir del montaje de la obra teatral en décimas La Negra Ester, de Roberto Parra. A partir de entonces, se gestará una tendencia que florece con el nuevo siglo en agrupaciones como Orquesta de la Memoria, La Regia Orquesta, Orquesta Tocornal, Flor de Orquesta, La Patogallina Saunmachin y Banda Conmoción entre otras. En ellas participan jóvenes con formación musical y teatral, que reinstalan el formato de la orquesta de teatro y de cabaret, dotándolo de componentes locales y carnavalescos.

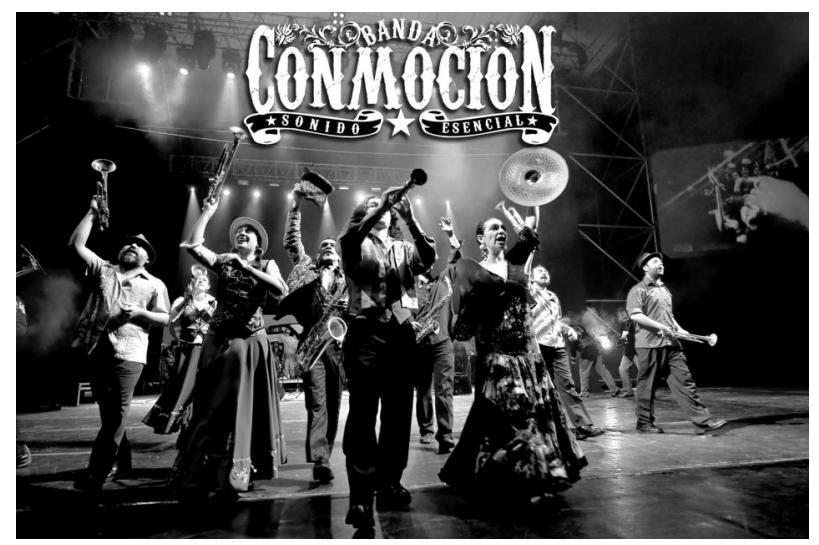

[7] Banda Conmoción www.myspace.com/bandaconmocion [10/2010]

La relación entre música y puesta en escena era desarroIlada en Chile desde mediados de los años cincuenta por el movimiento de música antigua y su idea de performance histórica. Esta tendencia instalaba en el escenario repertorio, instrumentos, prácticas y situaciones de escucha del pasado europeo y latinoamericano, inicialmente de los siglos XVI y XVII, pero luego expandiéndose al XVIII e incluso al XIX temprano. El Conjunto de Música Antigua de la Universidad Católica de Chile (1953), fue pionero en América Latina en esta tendencia, realizando una primera puesta en escena de música colonial y renacentista europea con su espectáculo El descubrimiento de América (1974) al que le siguió Tarde Isabelina -con el público sentado en un ambiente de taberna- y luego Historia de María ${ }^{10}$.

La escenificación de canciones y bailes antiguos, con la participación actores, músicos y cantantes, sirvió de base para la creación de la Compañía Del Salón al Cabaret (2002) en la Facultad de Artes de la Universidad Católica de Chile. Con esta compañía hemos realizado tres montajes o conciertos teatrales en los cuales escenificamos repertorio, grupos instrumentales, prácticas de canto y situaciones de escucha de la música popular en Chile entre 1900 y $1960^{11}$.

Al retroceder en el tiempo, las influencias musicales de la performance histórica se diversificarán, como ocurre con los conjuntos de música medieval, abiertos a raíces mediterráneas, hebreas, árabes y celtas. A la tendencia impuesta por estos conjuntos, se suma la aparición de un nuevo neomedievalismo a fines del siglo $X X$, estimulado por el culto posmoderno a la diversidad y por el cambio de milenio. El auge de los juegos de rol, la tendencia new age, algunos best sellers -desde el Nombre de la Rosa al Código Da Vinci- y la saga de El Señor de los Anillos, son ejemplos masivos de este neomedievalismo, de donde también surgió el boom internacional de la música celta ${ }^{12}$.

Este boom llegó a Chile a mediados de los años noventa, amparado por pubs irlandeses de Santiago, Valparaíso y Coquimbo, talleres de danzas antiguas, prácticas artísticas escolares, sellos independientes y fanáticos del mundo de los druidas. Además, en 1995 se presentaba en Santiago el arpista suizo de música new age Andreas Vollenweider, quien también incorpora raíces celtas a su práctica musical. Es así como el grupo chileno Viento Celta (19982003) alcanzará los primeros lugares de venta de discos de música new age en Chile, mientras la prensa contabilizaba diecisiete grupos de música y baile celtas activos en el país en $2003^{13}$.

Al teatro carnavalesco, a las prácticas históricas de la música antigua, y al neomedievalismo de raíz celta en el desarrollo de esta segunda iniciativa de expansión de raíces en tiempos de globalización, se sumará la influencia del cine de Emir Kusturika y de The No Smoking Orchestra. Su música unza-unza, mezcla de ritmos gitanos con actitud del punk, improvisación de jazz y condena explícita al pop, resultaba altamente atractiva y convocante para músicos 
y público chilenos del nuevo siglo. En ella encontraban un espíritu carnavalesco y desenfadado al que no se podian resistir.

Los recitales de The No Smoking Orchestra en Chile -teloneados por la banda local de raíz gitana La Mano Ajena- produjeron un fuerte impacto en el público y los músicos nacionales. Un ejemplo de esto son las razones subidas al sitio carretes.cl para obtener entradas gratuitas para el concierto de The No Smoking Orchestra en Viña del Mar en enero de 2010. El portal subió 553 de ellas, que expresan muy bien el fervor del público chileno por la música gitana ${ }^{14}$ :

Patricia: Este deleite... este manantial de energía que me sumerge en un mundo de sentidos, creaciones y felicidad extrema... Este Arte en movimiento... y vibraciones... que me hace bailar cuando traspasa por mis oídos.

Macarena: Porque en mi vida anterior fui gitana, y necesito fervientemente escuchar a Kusturica pa' que mi alma pueda volver a reencarnar, que la música Balcánica es más que oído, va por la sangre!! (de esa que hierve al bailar!!).

Rodrigo... mi sangre se revoluciona con esta música. No sólo disfruto escucharla sino que también disfruto interpretarla con mi violín. Por eso ir a verlo sería inolvidable!

La primera década del nuevo siglo culminaba en Santiago con dos "Cumbres gitanas", la segunda era organizada por La Mano Ajena en el Galpón Víctor Jara en mayo de 2010. Este galpón de la Fundación Víctor Jara constituye también el legado artístico del cantautor, de modo que lo que se presenta allí establece un diálogo simbólico con dicho legado. La música gitana en el Galpón Víctor Jara se suma, entonces, a la tendencia renovadora y expansiva de las raíces desarrollada por este cantautor desde mediados de los años sesenta.

Al considerar una raíz gitana en la práctica musical chilena, no podemos responsabilizar solamente al factor globalizante de la cultura en esta insospechada expansión de las raíces folklóricas. Los canales para la influencia gitana provenienen de prácticas artísticas de larga data, como son la de los músicos itinerantes y la del cine, gran difusor de músicas populares en el mundo. Además, la globalización entrega todas las influencias posibles, tanto pasadas como presentes, pero sólo algunas de ellas son escogidas localmente para nutrir hidropónicamente las nuevas raíces.
Los músicos de La Orquesta de la Memoria expresan muy bien esa libre elección de influencias, reconociendo dos tipos de ellas: las internas, que les llegan a través de su familia y educación, y las externas. En el reconocimiento de sus influencias internas, buscan adherirse a una tradición popular, que es la de los abuelos, reivindicando su pertenencia a lo que Ilaman "las cuatro esquinas" de la música popular: la cumbia, el foxtrot, el tango y el vals peruano, toda música vigente en Chile desde hace cincuenta años y más. La adhesión de La Orquesta de la Memoria a la música de los abuelos es realizada desde la calle, como espacio de fiesta y de resistencia cultural, afirma el grupo ${ }^{15}$.

El vínculo con la música de los abuelos es un fenómeno que se manifiesta con fuerza a partir de la condición posmoderna y su cuestionamiento de las certezas absolutas de la modernidad. A cambio de certezas se busca autenticidad y un modo de encontrarla es reinstalando prácticas musicales del pasado vinculadas a sujetos y circuitos percibidos como más puros y tradicionales. Estas músicas constituyen un remanso sonoro dentro de la gran complejidad y volumen del entorno musical contemporáneo. Al presentarse en un vídeo promocional, los músicos de La Orquesta de la Memoria destacan la autenticidad e independencia de su propuesta ${ }^{16}$.

Estupendo Ramírez (guitarra): Nosotros más que estudiosos hemos vivido el rollo. Igual hemos tocado en las micros [buses urbanos]; igual hemos tocado en las calles o trabajamos en otras cosas y luego ensayamos... así nos tocó.

Señor Don Javi (bajo): Hemos estado "donde las papas queman", resistiendo junto a los okupas, en los techos de los colegios durante las protestas estudiantiles...

Avelino Caín del Misterio (batería): Agarrar memoria emotiva, memoria familiar y construir algo al margen de un mercado saturado tanto de lo malo como de lo bueno.

El uso de apodos o nombres artísticos por los integrantes de La Orquesta de la Memoria corresponde a tendencias juveniles ligadas al punk, al hip-hop y a los Djs, aunque ya era usada por algunas estrellas del pop de los años ochenta. Lo nuevo es que ahora es todo el grupo el que utiliza nombres artísticos, como lo empezó a hacer la banda neoyorquina de punk The Ramones (1974), cambiando el apellido de sus integrantes al de Ramone. Sin embargo, en La Orquesta de la Memoria, esta tendencia adquiere un nuevo sentido, que es performático, como afirma Carolina 
Benavente, "mediante el cual se pretende la construcción deliberada de un personaje, donde antes más bien se designaba a una persona, acogiendo las variaciones y desviaciones de sus apelativos sociales"17.

Dentro de sus influencias externas, La Orquesta de la Memoria construye músicos-personajes y adopta la vertiente unza-unza de la música gitana, con su componente punk, y la mezcla con su influencia familiar, generando lo que denominan un "ritmo de burdel, arrabal y velorio". De este modo, La Orquesta de la Memoria busca una música transversal y mestiza, de ambientes sórdidos de un pasado actualizado mediante el acto teatral a través de la música.

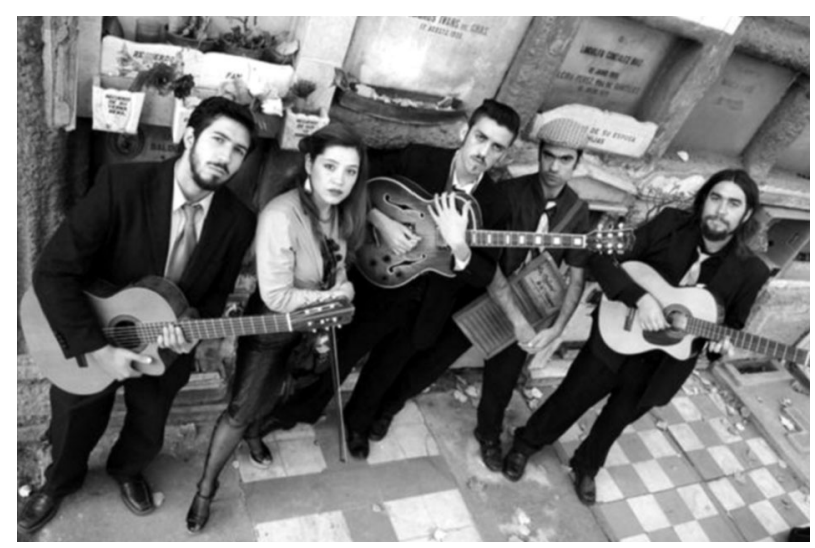

[8] Orquesta La Memoria www.laorquestadelamemoria.tk [10/2010]

\section{Palabras finales}

Con ejemplos como los de la tercera generación de cantautores chilenos y los grupos musicales surgidos de la escena teatral, podemos hablar más bien de una sensibilidad globalizada que de una cultura globalizada. Esa sensibilidad alimenta una actitud que permite la expansión de las posibles raíces tanto en el espacio como en el tiempo. Si por un lado tenemos el impacto internacional de la música gitana y del folklore de Europa del Este, por el otro tenemos el rescate de los años cincuenta, como ya venía ocurriendo con Buena Vista Social Club (1997), producido por Ry Cooder, o El Café de los Maestros (2008), producido por Gustavo Santaolalla. La restitución de prácticas performativas del pasado y la búsqueda de autenticidad e incorporación de alteridades culturales, se adscribe al revival histórico también presente en la world music, donde lo actual, entonces, es recurrir a lo que no lo es.

La expansión espacio/temporal de las raices ha sido realizada por músicos y productores bajo el manto legitimador del multiculturalismo posmoderno, expresado desde la industria discográfica por el concepto de world music, que incrementa la pluralidad sonora a la que se exponen tanto auditores como músicos. Esto facilita las mezclas espacio/ temporales y la consiguiente multiplicación de identidades intermedias más que monolíticas. En suma, estamos ante una reivindicación de lo local que es de lo Local con mayúsculas, donde todas las localidades son una sola y todos los tiempos nos pertenecen.

\section{NOTAS}

Recibido: 21 de noviembre de 2010 Aceptado: 15 de enero de 2011
1 Una versión preliminar de este texto fue presentada como ponencia en el III Congreso lberoamericano de Cultura "Las Músicas Iberoamericanas en el Siglo XXI", Medellín, Ministerio de Cultura de Colombia, 1 al 4 de julio de 2010.

2 Más sobre esto en González, Ohlsen y Rolle, 2009.

3 Gálvez, 1988, 264.

4 Donoso, 2008, 239.

5 Ver artículo de Katia Chornik sobre uso de "Candombe para José" por los presos políticos chilenos en http:// news.bbc.co.uk/hi/spanish/latin_ america/newsid_4174000/4174846. stm [11/2010]

6 La Bicicleta, 11, 3-4/1981, 7.

7 Agustín Ruiz en lista de la Asociación Chilena de Estudios de Música Popular, asempch@googlegroups.com (9/6/2010)

8 Más sobre programas de televisión dedicados al folklore en los años ochenta en Donoso, 2008, 269-271.

9 Comunicación personal de Horacio Salinas, director de Inti-illimani, Roma, agosto de 1988. Esto lo hicieron sin 
descuidar la ampliación de sus influencias latinoamericanas, enfatizando las de procedencia afro-peruana.

10 Ver Subercaseaux, 1997.

11 Más sobre esta experiencia en González, 2005.

12 En su ensayo "Dreaming of the Middle Ages" del libro Travels in Hyper Reality (1990), Humberto Eco entrega abundantes ejemplos de novelas y comics disponibles en la actualidad con visiones fantásticas de la época medieval.

13 La Nación, 9/2/2006.

14 www.carretes.cl [30/1/2010]

15 En www.youtube.com/watch?v=cm0 fVEhOoY4 [7/7/2010]

16 En www.youtube.com/watch?v=cm0 fVEhOoY4 [7/7/2010]

17 Carolina Benavente, lista de la Asociación Chilena de Estudios en Música Popular, asempch@googlegroups. cl (4/11/2010).

\section{BIBLIOGRAFÍA}

Bravo, Gabriela y Cristián González (2009): Ecos del tiempo subterráneo. Las peñas en Santiago durante el régimen militar (1973-1983), Santiago: LOM.

Claro, Samuel, Juan Pablo González, Carmen Peña y María Isabel Quevedo (1989): Iconografía musical chilena Santiago: Editorial Universidad Católica.

Donoso, Karen (2008): “Canción huasa o canto nuevo? La identidad chilena en la visión de izquierdas y derechas, 1973-1989", en Verónica Valdivia et al., Su revolución contra nuestra revoIución. La pugna marxista-gremialista en los ochenta, Volumen 2, Santiago: LOM Ediciones, 231-290.

Donoso, Karen (2009): "Por el arte-vida del pueblo: Debates en torno al folclore en Chile, 1973-1990", Revista Musical Chilena, 63/212: 29-50.
Eco, Humberto (1990): Travels in Hyper Reality, San Diego: Harvest/HBJ.

Gálvez, Hernán (1988): La gaviota de la ilusión, Santiago: Mompracem.

González, Juan Pablo, Oscar Ohlsen y Claudio Rolle (2009): Historia social de la música popular en Chile, 1950-1970, Santiago: Ediciones Universidad Católica de Chile, coautores.

González, Juan Pablo (2005): "The Making of a Social History of Popular Music in Chile: Problems, Methods and Results", Latin American Music Review, 26/2: 248-272.

http://cumbregitana.blogspot.com/ [20/10/2010]

Subercaseaux, Juana (1997): "El Instituto de Música de la Pontificia Universidad Católica", Resonancias, 1, 34-42.

www.youtube.com/watch? $\mathrm{v}=\mathrm{cmOfVEhOoY4}$ Orquesta de la Memoria, testimonios de sus cinco integrantes [7/7/2010]. 